\title{
Engineering photosynthetic organisms for the production of biohydrogen
}

\author{
Alexandra Dubini $\cdot$ Maria L. Ghirardi
}

Received: 18 November 2013/Accepted: 17 February 2014/Published online: 27 March 2014

(C) The Author(s) 2014. This article is published with open access at Springerlink.com

\begin{abstract}
Oxygenic photosynthetic organisms such as green algae are capable of absorbing sunlight and converting the chemical energy into hydrogen gas. This process takes advantage of the photosynthetic apparatus of these organisms which links water oxidation to $\mathrm{H}_{2}$ production. Biological $\mathrm{H}_{2}$ has therefore the potential to be an alternative fuel of the future and shows great promise for generating large scale sustainable energy. Microalgae are able to produce $\mathrm{H}_{2}$ under light anoxic or dark anoxic condition by activating 3 different pathways that utilize the hydrogenases as catalysts. In this review, we highlight the principal barriers that prevent hydrogen production in green algae and how those limitations are being addressed, through metabolic and genetic engineering. We also discuss the major challenges and bottlenecks facing the development of future commercial algal photobiological systems for $\mathrm{H}_{2}$ production. Finally we provide suggestions for future strategies and potential new techniques to be developed towards an integrated system with optimized hydrogen production.
\end{abstract}

Keywords Green algae $\cdot \mathrm{H}_{2}$ metabolism $\cdot$ Hydrogenases . Electron transfer - Genetic engineering

\section{$\mathrm{H}_{2}$ energy carrier}

Microalgae have gained relevance recently as versatile organisms that are able to harvest solar energy and convert it into a variety of products of commercial significance,

\footnotetext{
A. Dubini $(\bowtie) \cdot$ M. L. Ghirardi

National Renewable Energy Laboratory, 15013 Denver West

Parkway, Mail Box 3313, Golden, CO 80401, USA

e-mail: alexandra.dubini@nrel.gov
}

from nutraceuticals to fuels. One of the useful products of algal metabolism is the energy carrier hydrogen $\left(\mathrm{H}_{2}\right)$. Besides being the third most abundant element on the earth, $\mathrm{H}_{2}$ can be produced by a variety of sustainable technologies and can be easily interconverted into electricity for storage and transport. One of the major advantages of $\mathrm{H}_{2}$ as an energy carrier is the fact that its combustion does not release toxic products. Available technologies for production of $\mathrm{H}_{2}$ gas mostly involve reforming methanol. However, sustainable methods to extract $\mathrm{H}_{2}$ from water through photocatalytic, nuclear, photobiological, or photohybrid water electrolysis are being explored and offer the potential for a totally carbonneutral process. Moreover, the use of wind turbines to drive water electrolysis and generate $\mathrm{H}_{2}$ is being tested as a feasible technology to store energy during off-peak hours.

Many microalgae have a $\mathrm{H}_{2}$-centered metabolism in which $\mathrm{H}_{2}$ serves as a source of reductant, and protons act as a sink for intracellular reductant under different environmental conditions. Of major interest, though, is the fact that microalgae are able to directly link photosynthetic water oxidation to $\mathrm{H}_{2}$ production by hydrogenases, thus holding the promise of plentiful energy from essentially inexhaustible sources-water and sunlight.

\section{Microalgae $\mathrm{H}_{2}$ pathways}

As many other chlorophytes, the green unicellular alga Chlamydomonas reinhardtii is capable of producing $\mathrm{H}_{2}$ following a period of anaerobic induction (Gaffron and Rubin 1942; Healey 1970). Its genome is sequenced (Merchant et al. 2007), and many genetic and genomic tools to manipulate this organism are available. Indeed, Chlamydomonas is often called the "green yeast," due to 
the power of its genetic system, while also having all the advantages of a microbe: facile genetics, flexible metabolism, and growth under heterotrophic, autotrophic, and mixotrophic conditions. As such, it has been used as a model organism to improve our understanding of $\mathrm{H}_{2}$ metabolism in microalgae and to provide a test bed for different hypotheses to optimize $\mathrm{H}_{2}$ production for commercial applications.

The photoproduction of $\mathrm{H}_{2}$ by Chlamydomonas is linked to photosynthesis, whereby light energy is converted into chemical energy as per the $Z$ scheme (Ghirardi et al. 2009). In short, light absorbed by photosystem II (PSII) induces a charge-separated state involving $\mathrm{P}_{680^{+}}$and Pheophytin ${ }^{-}$ that extracts electrons from water, releasing $\mathrm{O}_{2}$ and protons into the chloroplast lumen. Concomitantly, light absorbed by photosystem I generates a strong oxidant $\mathrm{P} 700^{+}$that oxidizes an intermediate electron carrier (usually plastocyanin-PCY); the electron released from P700 reduces the electron acceptor ferredoxin (FDX). In linear electron flow (LEF), the electrons originated from PSII are transferred initially to plastoquinone (PQ) and, through a chain of carriers, reduce PCY. The final PSI electron acceptor, FDX, transfers electrons to the ferredoxin-NADP oxidoreductase (FNR) that in turn reduces $\mathrm{NADP}^{+}$to $\mathrm{NADPH}$, which is then consumed in the $\mathrm{CO}_{2}$ fixation reactions. Under anoxic conditions, FDX is also able to reduce the hydrogenases, catalyzing the reversible reduction of protons into molecular hydrogen (Florin et al. 2001).

There are three known hydrogen production pathways that contribute to $\mathrm{H}_{2}$ metabolism in Chlamydomonas. Two of those are mediated by the photosynthetic electron transfer chain, one being PSII dependent (direct pathway, described above) and the other PSII independent (indirect pathway). In the latter, reductant released from the glycolytic degradation of glucose are transferred through the enzyme NADP/plastoquinone oxidoreductase (NPQR) directly to the plastoquinone pool, bypassing PSII. On subsequent illumination, electrons are transferred down to the photosynthetic chain, reduce PCY, and are then reenergized by PSI and connected with the hydrogenase as in the direct pathway. Finally, the third $\mathrm{H}_{2}$-production pathway, which is linked to fermentation, is activated under dark anoxia and requires electron transfer from pyruvate to the hydrogenase through the pyruvate-ferredoxin-oxidoreductase (PFR). It is important to note that Chlamydomonas possesses two hydrogenases, HYDA1 and HYDA2 that can evolve $\mathrm{H}_{2}$ under anoxia through all of the three pathways (Meuser et al. 2012).

Although the potential energy conversion efficiency from sunlight to $\mathrm{H}_{2}$ by microalgae is theoretically high (about $10 \%$ ), $\mathrm{H}_{2}$ production is currently limited by biochemical and engineering constraints. Specific limitations include (a) the extreme sensitivity of the hydrogenases to
$\mathrm{O}_{2}$; (b) low reductant availability for hydrogenase activity due to the existence of competing metabolic pathways that converge at the level of ferredoxin (FDX); (c) downregulation of photosynthetic electron transport and establishment of cyclic electron transfer around PSI under anaerobic, $\mathrm{H}_{2}$-producing conditions; (d) the low level at which light saturation occurs in photosynthesis; (e) the reversible nature of hydrogenases that results in consumption of $\mathrm{H}_{2}$ under high $\mathrm{H}_{2}$ partial pressure; and (f) the low levels of hydrogenase expression. Here we discuss in more detail each of the barriers mentioned above and describe the different genetic modification approaches that are being pursued to circumvent them and have led to improved hydrogen production (Fig. 1; Table 1).

\section{Barriers}

$\mathrm{O}_{2}$ sensitivity of hydrogenases

Anaerobiosis is a prerequisite for $\mathrm{H}_{2}$ production by algae. Indeed, Chlamydomonas cultures are capable of photoproducing hydrogen at a very high efficiency (close to the maximal photosynthesis yield $\sim 10 \%$ ) for a few minutes upon illumination. The process stops due to, among other barriers, the inactivation of the hydrogenase by $\mathrm{O}_{2}$ generated at PSII. Various approaches have been utilized to overcome this inactivation (see "Genetic engineering to overcome limitations to hydrogen production" section below). The most successful one is based on the selective inactivation of PSII $\mathrm{O}_{2}$ evolution activity by sulfur deprivation (Melis et al. 2000). The sulfur-deprived system is usually operated in two stages. In the first stage, sulfurdeprived and illuminated cultures gradually inactivate PSII (the absence of sulfur prevents repair of photodamaged PSII) and simultaneously overaccumulate starch. When the rate of $\mathrm{O}_{2}$ photoproduced by PSII matches the rate of $\mathrm{O}_{2}$ consumption by respiration, the cultures become anaerobic. During the second stage, the residual PSII activity and concomitant starch degradation supply reductant to the photosynthetic chain through the operation of the direct and indirect electron transport pathways (Posewitz et al. 2005) and enable $\mathrm{H}_{2}$ photoproduction to occur. This approach, although convenient for laboratory studies, is, however, not scalable for commercial purposes due to its low inherent conversion efficiency (James et al. 2008).

Other approaches to circumventing the $\mathrm{O}_{2}$-sensitivity problem require either engineering an $\mathrm{O}_{2}$-tolerant algal [FeFe]-hydrogenase (Chang et al. 2007) or expressing a hydrogenase that is more tolerant to $\mathrm{O}_{2}$ in Chlamydomonas. Molecular dynamics simulations, solvent accessibility maps, and potential mean energy estimates have been used to identify gas diffusion pathways in model enzymes 


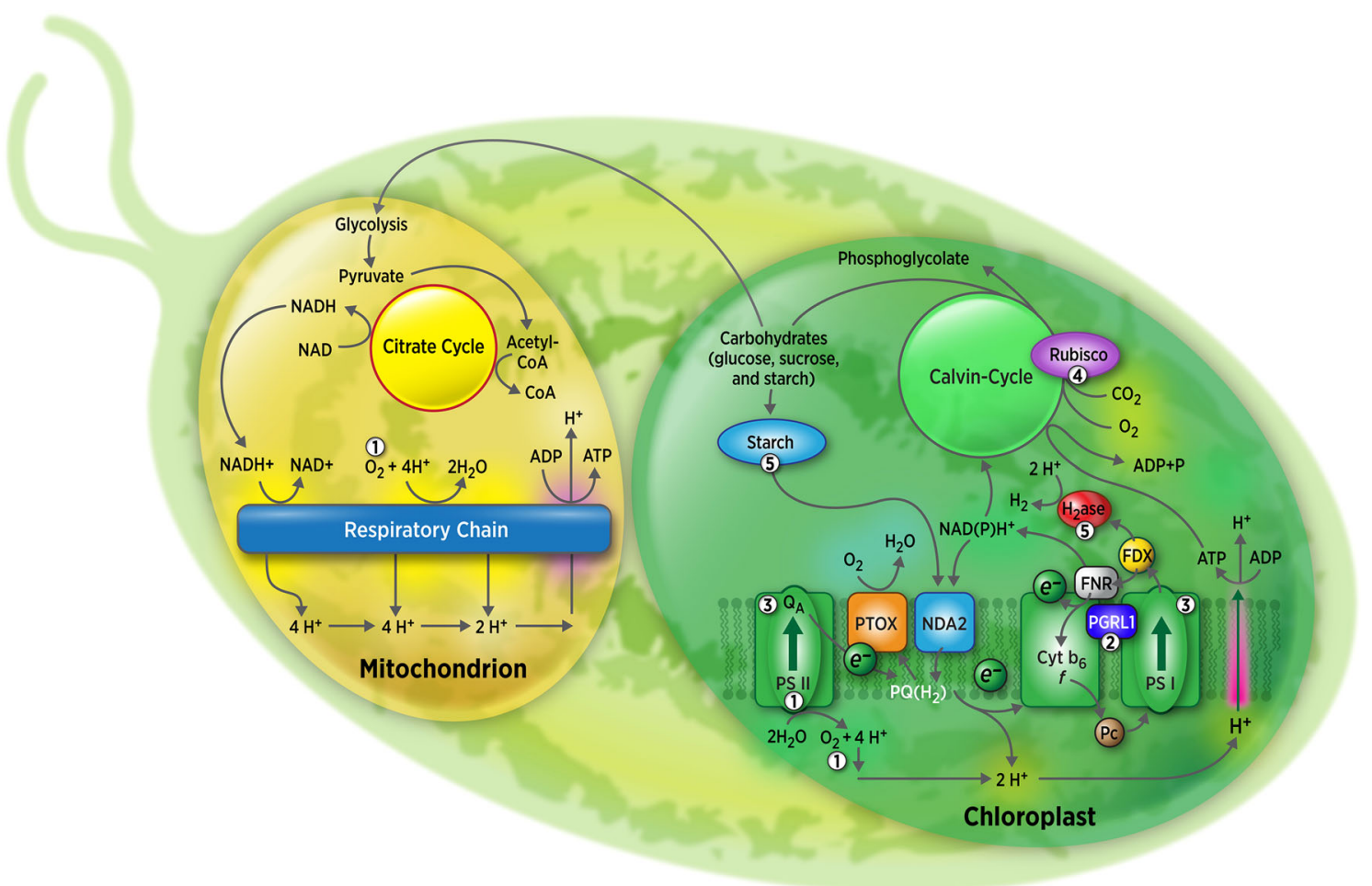

Fig. 1 Representation of the hydrogen photoproduction-related pathways in Chlamydomonas. Hydrogen production occurs in the chloroplast, where the photosynthetic chain and the hydrogenases are located (see text for more details). The respiratory chain is located in the mitochondrion, and there is an extensive communication between the two organelles that can impact the level of hydrogen production (adapted from Kruse et al. 2005). The circled numbers indicate where current genetic engineering efforts have impacted $\mathrm{H}_{2}$ photoproduction, as described in the text. The barriers overcome by these modifications are: (1) $\mathrm{O}_{2}$ sensitivity, addressed by PSII

(Chang et al. 2007), followed by site-directed mutagenesis (Long et al. 2009). However, this approach has not been successful due to the unexpected observation that the amino acid residues responsible for binding of the catalytic cluster are also involved in the formation of the gas channels (Mulder et al. 2010). Thus, mutants affecting these residues are unable to properly fold the protein. This observation explains the lower activity and higher $\mathrm{O}_{2}$ sensitivity of mutants that were generated based on the information provided by the computational models (Liebgott et al. 2010).

\section{Non-dissipated proton gradient and state transitions}

The anaerobic treatment used to induce $\mathrm{H}_{2}$ production in both sulfur-replete and -depleted cultures triggers starch degradation, causing reduction of the PQ pool through the NPQR enzyme. These conditions poise the cultures in state 2 and, upon illumination, trigger the CEF mode-which contributes to an increase in the proton gradient that normally drives ATP synthesis through the ATP synthase enzyme. In inactivation and/or increased $\mathrm{O}_{2}$ consumption; (2) proton gradient dissipation, addressed by the pgrll knockout mutation (decreased CEF); (3) photosynthetic efficiency, addressed by knockdown of light-harvesting antennae or truncating antenna proteins; (4) competition for electron, addressed by Rubisco mutagenesis; (5) low reductant flux and hydrogenase expression, addressed by impacting starch accumulation/degradation, FDX-HYD fusion, and overexpressing hydrogenase, respectively. It must be noted that, for clarity, not all the genetic engineering approaches mentioned in the text are represented in the figure

state 2, a fraction of the light-harvesting antenna of PSII gets connected to PSI, increasing its light-absorption cross section at the expenses of that of PSII and supposedly increasing CEF over LEF. However, since $\mathrm{H}_{2}$ photoproduction does not consume ATP, the proton gradient will remain undissipated when the anaerobically induced cells are illuminated. The non-dissipated proton gradient induces non-photochemical quenching mechanisms that lower the efficiency of photosynthetic electron utilization and thus of $\mathrm{H}_{2}$ production. The evidence for the effect of the non-dissipated proton gradient in $\mathrm{H}_{2}$ production is supported by the observation that proton uncouplers stimulate the rates of $\mathrm{H}_{2}$ photoproduction in sulfur-replete (Happe et al. 1994) and sulfur-depleted conditions [(Tolleter et al. 2011)—see "Barrier: proton gradient" section for further discussion]. Moreover, the influence of state 2 on downregulation of $\mathrm{H}_{2}$ production was confirmed by the recent report of a mutant locked in state 1I, stm6 (discussed in "Genetic engineering to overcome limitations to hydrogen production" section) that showed higher rates of $\mathrm{H}_{2}$ photoproduction than its parental strain (Kruse et al. 2005). 
Table 1 Summary of the genetically engineered strains with improved $\mathrm{H}_{2}$ production

\begin{tabular}{|c|c|c|c|c|c|c|}
\hline Barriers & Target & Strain & $\begin{array}{l}\text { Genetic } \\
\text { engineering } \\
\text { technique }\end{array}$ & Phenotype & $\begin{array}{c}\mathrm{H}_{2} \\
\text { production } \\
\text { vs control } \\
\text { strain }\end{array}$ & Ref \\
\hline \multirow[t]{7}{*}{$\mathrm{O}_{2}$ sensitivity } & D1 protein & L1591-N230Y & $\begin{array}{l}\text { Site-directed } \\
\text { mutagenesis }\end{array}$ & $\begin{array}{l}\uparrow q u a n t u m \text { yield } \\
\text { of photosynthesis } \\
\uparrow \text { respiration rate }\end{array}$ & $\begin{array}{l}\sim 20 \text { fold } \uparrow \\
\text { compared } \\
\text { to WT } \\
11 / 32 b\end{array}$ & $\begin{array}{l}\text { Torzillo } \\
2009\end{array}$ \\
\hline & PSII subunit O & antiPSBO & RNA interference & $\begin{array}{l}\uparrow \text { hydrogenase } \\
\downarrow \text { Fv/Fm }\end{array}$ & $\begin{array}{l}\sim 10 \text { fold } \uparrow \\
\text { compared } \\
\text { to WT } \\
\text { Chlorella } \\
\text { sp. DT }\end{array}$ & $\begin{array}{l}\text { Hsin Di Lin } \\
2013\end{array}$ \\
\hline & PSII & cyc6nac2.49 & $\begin{array}{l}\text { Random } \\
\text { mutagenesis }\end{array}$ & $\downarrow \mathrm{O}_{2}$ & $\begin{array}{l}\sim 3 \text { fold } \uparrow \\
\text { compared } \\
\text { to } n \text { ac } 2-26\end{array}$ & $\begin{array}{l}\text { Surzycki } \\
2007\end{array}$ \\
\hline & $\mathrm{P} / \mathrm{R}$ ratio & $\begin{array}{l}\text { aprl+ } \\
\text { glycoaldehyde }\end{array}$ & $\begin{array}{l}\text { DNA insertional } \\
\text { mutagenesis }\end{array}$ & $\begin{array}{l}\uparrow \text { respiration rate } \\
\downarrow \text { photosynthesis } \\
\text { rate }\end{array}$ & $\begin{array}{l}\sim 2-3 \text { fold } \uparrow \\
\text { compared } \\
\text { to CC-425 }\end{array}$ & Ruhle 2008 \\
\hline & $\begin{array}{l}\text { Leg } \\
\text { hemoglobin }\end{array}$ & $\begin{array}{l}\text { CC-849 } \\
\text { +codon } \\
\text { optimized } \\
\text { hemH-lbA }\end{array}$ & $\begin{array}{l}\text { Heterologous } \\
\text { expression from } \\
\text { Bradyrhizobium } \\
\text { and Glycine max } \\
\text { in } \\
\text { Chlamydomonas }\end{array}$ & $\begin{array}{l}\downarrow \text { growth } \\
\uparrow \mathrm{O}_{2} \text { consumption }\end{array}$ & $\begin{array}{l}\sim 4 \text {-fold } \uparrow \\
\text { compared } \\
\text { to CC-849 } \\
+ \text { non } \\
\text { codon } \\
\text { optimized } \\
\text { hemH-lbA }\end{array}$ & $\begin{array}{l}\text { Wu } 2010 \\
\text { Wu } 2011\end{array}$ \\
\hline & $\begin{array}{l}\text { Pyruvate } \\
\text { oxidase }\end{array}$ & $c c H P C$ & $\begin{array}{l}\text { Heterologous } \\
\text { expression from } \\
\text { E.coli in } \\
\text { Chlamydomonas }\end{array}$ & $\downarrow \mathrm{O}_{2}$ evolution & $\begin{array}{l}\sim 3 \text { fold } \uparrow \\
\text { compared } \\
\text { to CC-503 }\end{array}$ & Xu 2011 \\
\hline & $\begin{array}{l}\text { Sulfate } \\
\text { permase }\end{array}$ & antisulp & RNA Antisense & $\begin{array}{l}\downarrow \text { uptake sulfate } \\
\downarrow \mathrm{O}_{2} \text { evolution } \\
\downarrow \text { steady state } \\
\text { levels of PSII }\end{array}$ & $\begin{array}{l}\sim 4 \text { fold } \uparrow \\
\text { compared } \\
\text { to CW-15 }\end{array}$ & Chen 2005 \\
\hline Proton gradient & $\begin{array}{l}\text { Cyclic Electron } \\
\text { Flow PGRL1 } \\
\text { protein }\end{array}$ & pgrll & $\begin{array}{l}\text { DNA insertional } \\
\text { mutagenesis }\end{array}$ & $\begin{array}{l}\uparrow E T R \\
\downarrow N P Q\end{array}$ & $\begin{array}{l}\sim 3 \text { fold } \uparrow \\
\text { compared } \\
\text { to } 137 \mathrm{C}\end{array}$ & $\begin{array}{l}\text { Tolleter } \\
2011\end{array}$ \\
\hline State transition & $\begin{array}{l}\text { State } \\
\text { transitions }\end{array}$ & stm6 & $\begin{array}{l}\text { DNA insertional } \\
\text { mutagenesis }\end{array}$ & $\begin{array}{l}\uparrow \text { starch reserves } \\
\uparrow \text { respiration } \\
\text { No state } \\
\text { transitions } \\
\downarrow \text { PSII activity }\end{array}$ & $\begin{array}{l}\sim 5-13 \text { fold } \uparrow \\
\text { compared } \\
\text { to CC-1618 }\end{array}$ & $\begin{array}{l}\text { Kruse 2005, } \\
\text { Volgusheva } \\
2013\end{array}$ \\
\hline \multirow[t]{2}{*}{$\begin{array}{l}\text { Photosynthetic } \\
\text { efficiency }\end{array}$} & Antenna size & tlal & $\begin{array}{l}\text { DNA insertional } \\
\text { mutagenesis }\end{array}$ & $\begin{array}{l}\downarrow \text { Chl/reaction } \\
\text { center } \\
\uparrow \mathrm{O}_{2} \\
\text { evolution/Chl } \\
\uparrow \mathrm{H}_{2} \text { rate/Chl }\end{array}$ & $\begin{array}{l}\sim 4 \text { fold } \uparrow \\
\text { compared } \\
\text { to CC-4169 }\end{array}$ & $\begin{array}{l}\text { Kosourov } \\
2011 \text {, Polle } \\
2003\end{array}$ \\
\hline & $\begin{array}{l}\text { Light } \\
\text { harvesting } \\
\text { complex } \\
\text { LHCBM1,2,3 }\end{array}$ & stm6GLC4lo1 & RNA interference & $\begin{array}{l}\downarrow \mathrm{Chl} \\
\uparrow \mathrm{H}_{2} \text { rate/Chl }\end{array}$ & $\begin{array}{l}\sim 2 \text { fold } \uparrow \\
\text { compared } \\
\text { to } \\
\text { stm6GLC4 }\end{array}$ & Oey 2013 \\
\hline
\end{tabular}


Table 1 continued

\begin{tabular}{|c|c|c|c|c|c|c|}
\hline $\begin{array}{l}\text { Competition for } \\
\text { electron }\end{array}$ & $\begin{array}{l}\text { Rubisco large } \\
\text { subunit }\end{array}$ & CC-2803 & $\begin{array}{l}\text { DNA insertional } \\
\text { Mutagenesis }\end{array}$ & $\begin{array}{l}\text { Light sensitive } \\
\text { Reduced }\end{array}$ & $\begin{array}{l}\sim 2 \text { fold } \uparrow \\
\text { compared }\end{array}$ & $\begin{array}{l}\text { Heimscheier } \\
2008\end{array}$ \\
\hline & & & & $\begin{array}{l}\text { RuBisCo } \\
\text { Activity } \\
\downarrow \mathrm{O}_{2} \text { evolution }\end{array}$ & to $137 \mathrm{C}$ & \\
\hline & $\begin{array}{l}\text { Rubisco small } \\
\text { subunit }\end{array}$ & $Y 67 A$ & $\begin{array}{l}\text { Site-directed } \\
\text { mutagenesis }\end{array}$ & $\begin{array}{l}\text { Reduced } \\
\text { RuBisCo } \\
\text { Activity } \\
\downarrow \mathrm{O}_{2} \text { evolution }\end{array}$ & $\begin{array}{l}\sim 10 \text { fold } \uparrow \\
\text { compared } \\
\text { to } R B C S- \\
T 60-3\end{array}$ & Pinto 2013 \\
\hline \multirow[t]{2}{*}{$\begin{array}{l}\text { Low reductant } \\
\text { flux }\end{array}$} & Sugar reserve & stm6GLC4 & $\begin{array}{l}\text { Heterologous } \\
\text { expression of } \\
\text { HUP1 from } \\
\text { Chlorella in } \\
\text { Chlamydomonas }\end{array}$ & $\begin{array}{l}\text { Import glucose } \\
\uparrow \text { growth rate }\end{array}$ & $\begin{array}{l}\sim 1.5 \text { fold } \uparrow \\
\text { compared } \\
\text { to } \operatorname{stm} 6\end{array}$ & $\begin{array}{l}\text { Doebbe et al. } \\
2007,2010\end{array}$ \\
\hline & Starch enzyme & std3 sda6 & $\begin{array}{l}\text { DNA insertional } \\
\text { mutagenesis }\end{array}$ & $\begin{array}{l}\uparrow \text { residual starch } \\
\text { amounts }\end{array}$ & $\begin{array}{l}\sim 1.5 \text { and } \\
1.2 \text { fold } \uparrow \\
\text { compared } \\
\text { to } 137 \mathrm{C}\end{array}$ & $\begin{array}{l}\text { Chochois } \\
2010\end{array}$ \\
\hline $\begin{array}{l}\text { Low level of } \\
\text { hydrogenase }\end{array}$ & $\begin{array}{l}\text { Hydrogenase } \\
\text { from Chlorella } \\
\text { sp.DT }\end{array}$ & C.s DT hydA & $\begin{array}{l}\text { Homologous } \\
\text { overexpression in } \\
\text { Chlorella }\end{array}$ & $\uparrow \mathrm{Fv} / \mathrm{Fm}$ & $\begin{array}{l}\sim 7 \text { fold } \uparrow \\
\text { compared } \\
\text { to WT } \\
\text { Chlorella } \\
\text { sp. } D T\end{array}$ & Chien 2012 \\
\hline
\end{tabular}

For more details, refer to the text and references (adapted from Esquível et al. 2011). Note We followed the nomenclature set by the www. chlamy.org website for eukaryotic genes throughout the text. Genes are listed: uppercase letters, italics (nuclear encoded) or lowercase with the last letter uppercase, italics (chloroplast encoded); proteins in uppercase letter, no italics; mutant strains in lowercase, italics. Prokaryotic nomenclature is set as follow: Genes and mutant strains are listed in lowercase with the last letter uppercase, italics; proteins: first and last letter capital, italics

\section{Small antenna size}

As true of other photosynthetic processes, the efficiency of photohydrogen production by mass cultures under solar intensity is limited by the large antenna size of the photosystems. Under high light fluxes, the photons absorbed by the light-harvesting antennae of PSI and PSII are underutilized and are dissipated as fluorescence or heat. Thus, in a highdensity mass culture, cells at the surface overabsorb and waste sunlight; whereas cells deeper in the culture are deprived of light due to shading. The photosynthetic capacity of the cell is, therefore, not used at its maximum potential.

\section{Competition for photosynthetic reductant}

Algal $\mathrm{H}_{2}$ production is also limited by the existence of pathways that compete directly with the hydrogenase for photosynthetic reductant from ferredoxin. These include FNR, FTR (ferredoxin/thioredoxin reductase), nitrite reductase, sulfite reductase, and glutamate synthase. The activities of all these enzymes do have an impact on hydrogen production, since they decrease the electron flux toward hydrogenase depending on the physiological conditions in the cell. In Chlamydomonas, only two out of the six chloroplast-localized ferredoxins (FDXs), FDX1 and FDX2, are functionally linked to the hydrogenases. These two FDXs share similar binding partners but FDX1 serves as the primary electron donor to three important biological pathways, $\mathrm{NADP}^{+}$reduction, and $\mathrm{H}_{2}$-photo and fermentative production. FDX2 is also capable of driving these reactions but at less than half the rate observed for FDX1 (Noth et al. 2013; van Lis et al. 2013; Peden et al. 2013). Finally, FDX1 is also involved in transferring electron to PGRL1, the protein that mediates cyclic electron transfer through the Cyt b6/f complex.

\section{Genetic engineering to overcome limitations to hydrogen production}

Recent genetic engineering efforts have pushed forward the biohydrogen research area and provided additional insight into the complex interaction among the diverse pathways involved in the process. Next, we discuss some of the genetically modified strains that led to improved hydrogen production (see Table 1 for a summary of strain phenotypes).

\section{Barrier: $\mathrm{O}_{2}$ sensitivity}

Many attempts have been made to generate $\mathrm{O}_{2}$-tolerant hydrogenases through random mutagenesis in vivo (Ghirardi et al. 1997) and in vitro (Stapleton and Swartz 2010). 
Unfortunately, these efforts yielded only small changes in $\mathrm{O}_{2}$ tolerance. As an alternative approach, various research groups developed different methods to induce anaerobic conditions, either by partially inactivating PSII in order to decrease the rates of $\mathrm{O}_{2}$ evolution (as achieved by sulfur deprivation) or to increase $\mathrm{O}_{2}$ uptake/sequestration within the cell.

\section{Partial PSII inactivation}

The D1 protein is part of the PSII reaction center and, together with D2, binds the majority of the cofactors involved in the PSII-dependent electron transport. Most of the amino acid residues between S155 and D170 in D1 (Ohad and Hirschberg 1992; Lardans et al. 1998; Xiong et al. 1998) appear to be crucial in mediating electron transfer from the D1-Y161 (or donor Z) to P680 ${ }^{+}$(Hutchison et al. 1996), and some of them (e.g., D170) have been demonstrated to be crucial for binding the manganese cluster (Ohad and Hirschberg 1992; Nixon and Diner 1992; Chu et al. 1995). They are thus promising targets for mutagenesis aimed at inactivating PSII activity. The phenotypic characterization of the L1591-N230Y mutant in Chlamydomonas was recently reported (Scoma et al. 2012; Torzillo et al. 2009). This mutant has lower chlorophyll content, higher photosynthetic capacity, and higher relative quantum yield of photosynthesis, together with higher respiration rate and a very high conversion of violaxanthin to zeaxanthin during $\mathrm{H}_{2}$ production, suggesting better photoprotection under high light. This strain produced 20 times more $\mathrm{H}_{2}$ than the wild-type strain and for longer periods of time, thus validating the concept that partial PSII inactivation promotes higher $\mathrm{H}_{2}$-production activity.

Partial inactivation of $\mathrm{O}_{2}$ evolution was also reported in Chlorella sp. DT, and it was achieved by knocking down the $P S B O$ subunit of PSII. The authors used short interference RNA antisense- $P S B O$ fragments and observed that the HYDA gene transcription and the HYDA expression levels were increased in the psbo-knockdown mutants (Lin et al. 2013). Under low illumination and semi-aerobic conditions (the Chlorella native hydrogenase has increased tolerance to $\mathrm{O}_{2}$ ), they reported that photobiological $\mathrm{H}_{2}$ production increased by as much as tenfold compared to its WT (Lin et al. 2013).

Recently, a genetic switch was developed to regulate PSII activity and allow control of the oxygen level and electron flux in the cell (Surzycki et al. 2007). The switch is composed of the nuclear-encoded NAC2 chloroplast protein that is required for the stable accumulation of the $p s b D$ RNA (which encodes the PSII D2 reaction center protein), and the anoxia-dependent copper-sensitive cytochrome CYC6 promoter. A construct containing the two fused DNA sequences was used to control the expression of the D2 protein in transgenic strains. Under aerobic conditions, expression of $N A C 2$ is repressed, and the D2 protein becomes unstable, causing gradual loss of $\mathrm{O}_{2}$-evolution activity and leading to anaerobiosis and $\mathrm{H}_{2}$ production by the organism. The resulting anaerobic conditions induce resynthesis of NAC2 protein and result in increased stability of D2; under these conditions, $\mathrm{O}_{2}$ evolution is gradually restored and $\mathrm{H}_{2}$ production is inhibited. The alternate expression and repression of the $N A C 2$ gene, without the need for removing copper from the medium serves the same purpose as the sulfur-deprivation process described in " $\mathrm{O}_{2}$ sensitivity of hydrogenases" section, allowing the operation of a 2-phase system where carbon reserves accumulate during the oxygenic phases and subsequently support the respiratory activity needed to achieve anaerobiosis during the second phase. The authors report the production of $20 \mu \mathrm{mol} \mathrm{H}_{2} /$ liter during one cycle, which corresponds to a maximal rate of $1 \mathrm{mmol} \mathrm{H}_{2} \mathrm{~mol}^{-1} \mathrm{Chl} \mathrm{s}^{-1}$.

\section{Increased $\mathrm{O}_{2}$ consumption/sequestration}

Anaerobiosis can be achieved either by decreasing $\mathrm{O}_{2}$ evolution or increasing respiration, i.e., by manipulating the photosynthesis/respiration ratio ( $\mathrm{P} / \mathrm{R}$ ratio) and bringing it below 1. The aprl mutant, which exhibited an attenuated $\mathrm{P} / \mathrm{R}$ ratio (Ruhle et al. 2008), was shown to become anaerobic in the light, mimicking the physiological status of sulfur-deprived cells. In this strain, starch is degraded under non-stress conditions and the reducing equivalents are transferred by the $\mathrm{NAD}(\mathrm{P}) \mathrm{H}$ plastoquinone-oxidoreductase (NPQR, also called NDA2) to the plastoquinone pool (PQ) (Mus et al. 2005), keeping it reduced. As a consequence, CEF and photophosphorylation still occur, although PSII activity is substantially downregulated. The aprl mutant becomes anaerobic under photoheterotrophic, sulfur-replete conditions and induces hydrogenase synthesis in the light. However, it does not produce hydrogen, contrary to expectations. In the past, it has been shown that hydrogen production in anaerobically adapted algae is highest when the carbon dioxide concentrations are low (Cinco et al. 1993), due to competition between hydrogenase and FNR for photosynthetic reductant. Photoreduced FDX transfers electrons mainly to FNR, which then supplies NADPH to the Calvin-Benson Cycle. Thus, to disrupt the effect of the Calvin Benson cycle activity on hydrogen metabolism, glycolaldehyde (GA) was added to the aprl culture. GA disrupts the Calvin-Benson cycle activity by inhibiting the phosphoribulokinase, which catalyzes the ATP-dependent phosphorylation of ribulose-5-phosphate to ribulose-1,5-bisphosphate. Consequently, it was observed that the in vivo hydrogen production rate of aprl cell samples was twice the rate determined in WT sulfur- 
deprived cells, thus confirming the usefulness of the low P/R ratio concept (Ruhle et al. 2008).

Another approach to induce anaerobiosis is by introducing $\mathrm{O}_{2}$ sequesters into the chloroplast. Leghemoglobins (LbA) proteins sequester and carry $\mathrm{O}_{2}$ from the legumes' root nodules to symbiotic $\mathrm{N}_{2}$-fixing Rhizobia in order to keep the $\mathrm{O}_{2}$ levels low around their nitrogenase. The maturation of leghemoglobins requires the rhizobial hemH gene that encodes for a ferrochelatase, that is necessary for catalyzing the last step of heme synthesis (Frustaci and O'Brian 1992). Wu et al. 2010 cloned the hemH and the $l b A$ genes as a fusion construct, transformed them into the chloroplast of Chlamydomonas, and demonstrated that the expression of the respective fusion protein improved $\mathrm{H}_{2}$ yields by decreasing the $\mathrm{O}_{2}$ content in the medium; both in the presence and absence of sulfur $\mathrm{H}_{2}$ yields in transgenic algal cultures increased, to as much as fourfold in sulfurfree medium compared to the wild type, correlating to the highest expression levels of the HemH-LbA fusion protein in the cell. To further improve their yield, the authors generated a codon-optimized construct of the hemH gene and observed that the expression level of HemH-LbA protein increased 6.8-fold in the transgenic alga compared with the non-codon-optimized strain, resulting in a $22 \%$ increase in the $\mathrm{H}_{2}$ yield and an overall increase of $134 \%$ in $\mathrm{O}_{2}$ uptake compared to the control WT cultures (Wu et al. 2011).

Alternative approaches to remove $\mathrm{O}_{2}$ from the culture medium include the introduction of new pathways in Chlamydomonas that utilize $\mathrm{O}_{2}$. The enzyme pyruvate oxidase (PoX) catalyzes the decarboxylation of pyruvate to acetyl phosphate and $\mathrm{CO}_{2}$. Since this reaction requires $\mathrm{O}_{2}$, it was hypothesized that introducing this gene in Chlamydomonas could help decrease the intracellular $\mathrm{O}_{2}$ levels (Xu et al. 2011). In E. coli, pyruvate oxidase plays an important role in aerobic growth by maintaining the pool of free CoA (Flores et al. 2004). The transgenic alga expressing the E. coli poX showed low oxygen evolution and no defect on growth rate. Moreover, it was capable of producing hydrogen at twice the rate of its WT (Xu et al. 2011).

Finally, to recreate the effect of sulfur depletion in the cell, an antisense technology was applied to Chlamydomonas to probe the effect of the repression of the sulfate permease gene, SULP. As expected, the antisulp transformants were impaired in sulfate uptake, and exhibited a sulfur-deprivation phenotype, with strong induction of arylsulfatase activity and global induction of the expression of sulfate assimilation genes. The cells displayed slower rates of light-saturated oxygen evolution, lower levels of Rubisco, and lower steady-state levels of the PSII D1 reaction center protein, suggesting that attenuation of the SulP gene expression immediately affects the repair of PSII from photo-oxidative damage (Chen et al. 2005). The expression of the SULP gene also led to a lowering in PSII activity, establishing anaerobiosis more quickly in the cell. Under anaerobiosis, the antisulp strains produce less oxygen and photoevolve $\mathrm{H}_{2}$ (Chen et al. 2005).

In our view, methods based on partial inactivation of PSII by itself will not achieve high light-conversion efficiencies (James et al. 2008), even if they are combined with increased respiratory $\mathrm{O}_{2}$ consumption. However, the effect of expressing $\mathrm{O}_{2}$ sequesters, such as leghemoglobin and the pyruvate oxidase enzyme, in Chlamydomonas should be analyzed more carefully to determine (a) the total $\mathrm{O}_{2}$ binding capability of leghemoglobin molecules, and how the $\mathrm{O}_{2}$ is eventually released to the medium, and (b) the efficacy of the pyruvate oxidase reaction in long-term, high- $\mathrm{H}_{2}$-producing conditions. An additional approach under consideration involves the expression of one of the clostridial $[\mathrm{FeFe}]-$ hydrogenases in Chlamydomonas. These enzymes have been shown to have two orders of magnitude higher tolerance to $\mathrm{O}_{2}$ in vitro, and one needs to verify whether it maintains its higher $\mathrm{O}_{2}$ tolerance when physiologically connected to the Chlamydomonas photosynthetic apparatus as well.

\section{Barrier: proton gradient}

The downregulation of photosynthetic LEF by non-dissipation of the proton gradient in $\mathrm{H}_{2}$-producing cell was addressed by isolation of a mutant deficient in PGRL1, as described in "Non-dissipated proton gradient and state transitions" sections. The PGRL1 protein is a component of a supercomplex that includes PSI-LHCI-LHCII-FNRCytochrome b6/f; this supercomplex is proposed to mediate CEF, and its operation is induced by high light conditions. When PGRL1 is genetically disrupted, the CEF around PSI becomes non-operational (Tolleter et al. 2011). The pgrll mutant strain was shown to exhibit lower CEF and increased hydrogen production under both short-term (argon-induced) and long-term (sulfur-deprivationinduced) anaerobiosis under high light. The authors concluded that the proton gradient generated by CEF in WT cells under high illumination strongly limits the electron supply to hydrogenase, and it can be overcome by disrupting components of the supercomplex. Moreover, as expected, the mutant strain exhibited reduced NPQ, likely resulting from the decrease in the CEF-dependent proton gradient.

Although it has been shown recently that state transitions do not control CET (Lucker and Kramer 2013; Takahashi et al. 2013), a mutant blocked in state 1 (stm6) showed no CET, higher respiratory metabolism, large starch reserves, and a low dissolved $\mathrm{O}_{2}$ concentration (40\% of the wild type (WT)), resulting in increased 
hydrogen production following anaerobic induction. No direct effect on PSII activity was reported, possibly due to the fact that anaerobiosis could be achieved faster-thus protecting PSII from irreversible photoinhibition. The $\mathrm{H}_{2}$-production rates of were 5-13 times higher than the control WT strain over a range of conditions (light intensity, culture time, and addition of uncouplers). More recent studies demonstrated that most PSII centers are "closed" in the stm 6 mutant during the anaerobic phase, and that, under sulfur-deprivation conditions, water splitting by the remaining open PSII supplies the majority of electrons for $\mathrm{H}_{2}$ synthesis (Volgusheva et al. 2013).

Both of the mutants described above are currently being genetically combined with strains expressing other traits that overcome additional barriers, such as truncated antennae (see "Barrier: photosynthetic efficiency" section). However, we must point out that the host strain used to generate the stm6 mutant is a low $\mathrm{H}_{2}$ producer compared to other Chlamydomonas WT strains such as CC-124 and D66. It would be more useful if the stm6 mutant genotype were genetically transferred to one of these high $\mathrm{H}_{2}$-producing WT strains to increase the chance that it will achieve higher conversion efficiencies in the future.

\section{Barrier: photosynthetic efficiency}

The concept of decreasing the chlorophyll antenna size of the photosystems to increase the light utilization efficiency of algal mass cultures has been proposed in the past (Melis et al. 2000; Melis and Chen 2005). Research efforts to test it have focused on using random mutagenesis and highthroughput screening to aid the identification of genes that regulate the $\mathrm{Chl}$ antenna size in green alga. This work has resulted in strains with gradually smaller antenna sizes and increasing photosynthetic productivity (Polle et al. 2003; Tetali et al. 2007; Mitra and Melis 2010; Kirst et al. 2012a, b). Analysis of the Chlamydomonas tlal truncated antenna mutant proved that the concept is also successful in increasing $\mathrm{H}_{2}$ productivity. Kosourov et al. 2011 immobilized WT and tlal sulfur-deprived mutant cells on alginate fims and monitored long-term $\mathrm{H}_{2}$-photoproduction activity under light intensities ranging from 19 to $350 \mu \mathrm{E} \mathrm{m}^{-2} \mathrm{~s}^{-1} \mathrm{PAR}$. They showed that the mutant was able to produce $\mathrm{H}_{2}$ gas for over $250 \mathrm{~h}$ under all light conditions tested and exhibited a 4-8 times higher maximum specific rate between 285 and $350 \mu \mathrm{E} \mathrm{m}^{-2} \mathrm{~s}^{-1}$, compared to WT cells.

Along the same line, RNAi knockdowns of the lightharvesting complexes $\mathrm{M} 1,2$, and 3 were performed to reduce the antenna size and optimize light capture by Chlamydomonas. LHCBM1, 2, and 3 are known to be the most abundant LHC proteins, and knocking them down simultaneously reduced the total chlorophyll content of the cells-resulting in improved light penetration and utilization. This multiple mutant displayed higher photosynthesis light saturation level and did not suffer photoinhibition under saturating light intensity. Upon sulfur deprivation, the mutant strain showed an immediate onset of $\mathrm{H}_{2}$ production, indicating that the intracellular $\mathrm{O}_{2}$ levels were already poised to induce HYDA transcription. Furthermore, the rate of $\mathrm{H}_{2}$ production observed in this strain was twice as high as that of the stm6GLC4 (Oey et al. 2013) described below.

As mentioned in the previous section, both the tla and the lhcb mutants are being or have been introduced into strains that are not limited by the non-dissipation of the proton gtradient and will continue to serve as the host for other strains expressing additional useful traits.

\section{Barrier: competition for electrons}

The major pathway competing for photosynthetic reducing power with the hydrogenase is $\mathrm{CO}_{2}$ fixation, whose first step is $\mathrm{NADP}^{+}$photoreduction by FNR. Under oxic conditions, most of the photosynthetic reductant is directed from FDX1 to FNR-which produces NADPH. When the cells become anoxic, HYDA competes with FNR at the level of FDX1. In order to reduce this competition (and bypass the dominating effect of FNR), a ferredoxinhydrogenase fusion was engineered and tested in vitro (Yacoby et al. 2011). It was shown that the $\mathrm{H}_{2}$-photoproduction activity of the fusion was sixfold higher than that using isolated HYDA and added FDX. The authors proposed that the fusion successfully insulates FDX1 internal electrons from exogenous competitors, and demonstrated that only $10 \%$ of the photosynthetic electrons are lost to FNR in the absence of added FDX. Finally, they showed that the fusion was able to overcome $\mathrm{NADP}^{+}$competitive inhibition, as more than $60 \%$ of photosynthetic electrons were diverted to hydrogen production compared to less than $10 \%$ for non-fused HYDA (Yacoby et al. 2011).

The subsequent steps in $\mathrm{CO}_{2}$ fixation involve the carboxylation of ribulose bis-phosphate by the enzyme $\mathrm{Ru}-$ bisco. This enzyme plays an important role in the global carbon cycle and photorespiratory oxygen consumption. Thus, not surprisingly, strain CC-2803, which is impaired in $\mathrm{CO}_{2}$ fixation (lacking the large subunit of Rubisco), showed a higher rate of $\mathrm{H}_{2}$ production than its wild-type parent under sulfur deprivation (Hemschemeier et al. 2008). Similarly, an engineered Chlamydomonas strain harboring a mutation on tyrosine 67 of the Rubisco small subunit displayed 10- to 15 -fold higher hydrogen production rate than its WT (Pinto et al. 2013). This latter mutation was shown to impair the stability of Rubisco (Esquivel et al. 2006) and resulted in a decrease in efficiency and the amount of PSII protein complexes (Pinto et al. 2013). The phenotype was explained by the feedback 
inhibitory effect of eliminating a major electron sink on the generation of reductant/protons by PSII (Skillman 2008). It is also known that inhibition of the Calvin Cycle leads to over-reduction of the photosynthetic electron transport chain, thus promoting the generation of reactive oxygen species in PSII, which may have caused increased photoinhibition (Antal et al. 2010).

Barrier: low reductant flux to the hydrogenase

As mentioned above, in the presence of active $\mathrm{CO}_{2}$ fixation, the reductant flux available for hydrogen production is low. In order to increase this flux, a HUP1 (hexose uptake protein) hexose symporter from Chlorella kessleri was incorporated into the Chlamydomonas stm6 mutant strain (Doebbe et al. 2007). The rationale was to develop a strain capable of providing additional reductant to the hydrogenase by increasing the amount of respiratory substrate. This new engineered strain can use externally supplied glucose for heterotrophic growth in the dark. In the light, a 1.5-fold increase in $\mathrm{H}_{2}$-production capacity was observed. Coupling an external carbon source to $\mathrm{H}_{2}$ synthesis, thus, represents an alternative for feedstock utilization and fuel production (Doebbe et al. 2007).

Starch metabolism is an important factor for hydrogen production, since it is the source for reductant to the PSIIindependent (or indirect) pathway. To better understand the impact of starch degradation on hydrogen production, a mutant library was developed and screened for mutants affected in starch catabolism (Chochois et al. 2010). The results showed that mutants with the strongest impact on starch catabolism generally displayed lower hydrogen production by the PSII-independent pathway than their parental strains. On the other hand, while mutants that were only slightly affected in starch degradation exhibited a delay in their $\mathrm{H}_{2}$-production activity under sulfur deprivation. Two mutant strains showed a much higher total hydrogen production yield than the wild type, although they displayed different phenotypes. In the first, std3, the amount of starch accumulated under sulfur deprivation was similar to the wild type but the $\%$ of residual starch left at the end of the $\mathrm{H}_{2}$-production phase was lower-suggesting that faster degradation kinetics correlated with higher hydrogen production. The second mutant, sda6, showed a slow rate of starch degradation, accompanied by an initial $\mathrm{H}_{2}$-production rate that was lower than the WT; however, the final $\mathrm{H}_{2}$ yield was much higher than that of the WT. These studies support the relationship between the indirect hydrogen production pathway and starch catabolism, and emphasize the importance of its contribution to overall algal $\mathrm{H}_{2}$ photoproduction-signaling an alternative method to manipulate algal $\mathrm{H}_{2}$ production (Chochois et al. 2010).
Although experimental evidence demonstrates that overall $\mathrm{H}_{2}$-production rates increase in the presence of exogenous or higher endogenous levels of organic substrate, it is not clear whether this approach would result in a more cost-effective process, given that either (a) the cost of the organic substrate will increase the overall cost of the process or (b) the organism will have to undergo the sulfurdeprivation process to induce endogenous carbon substrate catabolism and hydrogenase activity-which has been shown to have overall unsatisfactory light-conversion efficiency (James et al. 2008).

It must be noted that the low level of hydrogense gene expression or the rapid turnover of the protein due to presence of oxygen was also proposed to contribute to the low level of $\mathrm{H}_{2}$ production. Homologous overexpression of the Chlorella sp. DT hydrogenase shows that it is possible to increase hydrogen production by overexpressing the enzyme. This alga contains a hydrogenase that is more oxygen tolerant than the Chlamydomonas enzyme, and is capable of producing small amounts of hydrogen under aerobic and sulfur-replete conditions. The overexpression of this enzyme in the native host led to 7- to 10-fold increase in hydrogen production yield (Chien et al. 2012).

This is a promising approach that could be attempted in high $\mathrm{H}_{2}$-producing algae, such as Chlamydomonas or combined with methods to sequester photosynthetically evolved $\mathrm{O}_{2}$ in Chlorella.

\section{Additional potential bottlenecks in hydrogen production}

Biological hydrogen photoproduction is a complex process that requires a tight control/regulation of many pathways at different levels. Genetic engineering has been employed to overcome these limitations and, in most cases, hydrogen production rates have been improved. However, additional genetic modification will be required to achieve maximal conversion efficiency of solar energy into biohydrogen. These include but are not limited to (a) designing an inducible leaky ATP synthase mutant and/or inducible proton channel, whereby the proton gradient is dissipated while the cell produces $\mathrm{H}_{2}$; (b) increasing the size of the PQ pool to ameliorate the rate-limiting step in photosynthetic electron transport, the oxidation of the PQ pool; and (c) overexpressing NDA2 to increase electron flux into and from the indirect hydrogen production pathway.

\section{High-throughput screening techniques}

To screen for mutants altered in $\mathrm{H}_{2}$ production, several techniques have been developed in the past years as 


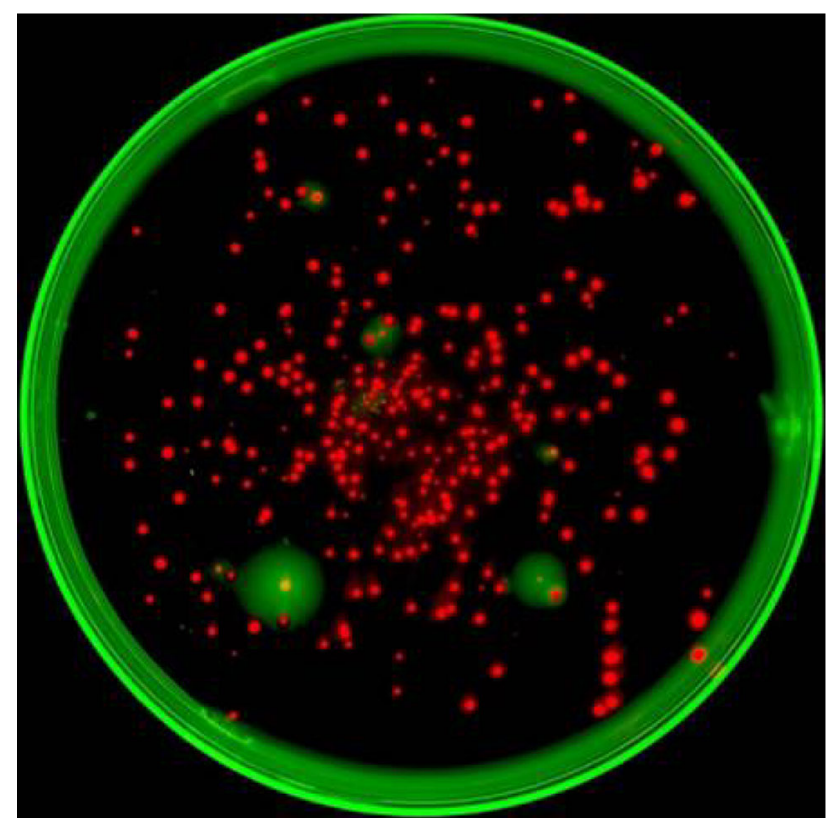

Fig. 2 Detection of $\mathrm{H}_{2}$ photoproduction by algal colonies at high light fluxes using the $R$. capsulatus emGFP overlay screening assay. Composite images indicating $\mathrm{H}_{2}$ production in green and colony density in red, as taken with a Fluorchem Q imaging system, are shown. Transformants from a Chlamydomonas reinhardtii insertional mutagenesis library were plated on hygromycin plates, and overlaid with the Rhodobacter capsulatus GFP-based $\mathrm{H}_{2}$-sensing system. The plate was incubated for $16 \mathrm{~h}$ at $300 \mu \mathrm{E} \mathrm{m}^{-2} \mathrm{~s}^{-1}$ light prior to fluorescence imaging. The figure shows four strains capable of $\mathrm{H}_{2}$ production at this light level (Wecker et al. 2011)

described below. One of the best available methods is a solid-state chemochromic $\mathrm{H}_{2}$ sensor consisting of tungsten oxide and palladium. The palladium captures $\mathrm{H}_{2}$ and transfers it to the tungsten oxide which turns blue when reduced. Chlamydomonas insertional mutants plated on Petri dishes were screened for attenuated hydrogen production following induction in an anaerobic glove box overnight. When exposed to the light, the cells photoevolved $\mathrm{H}_{2}$, which was detected as blue dots on the $\mathrm{H}_{2}$ sensor (Seibert et al. 2001; Flynn et al. 2002). This method was successfully used to identify the hydrogenase catalytic cluster assembly genes HYDEF and HYDG (Posewitz et al. 2004a) and a starch-less mutant, sta7, in which hydrogenase gene transcription is repressed (Posewitz et al. 2004b).

A water-soluble color indicator has also been used to screen hydrogen-producing microorganisms. This indicator consists of a coloring agent and a water-soluble derivative of Wilkinson's catalyst [Tris(triphenylphosphine) rhodium chloride]. In this screen, methyl orange and the sulfonate catalyst are dissolved in water and change color when in contact with hydrogen gas. This system can be used with any $\mathrm{H}_{2}$-producing microorganism (Katsuda et al. 2006).

Finally, a new and very sensitive technique was recently developed, based on the sensing system from Rhodobacter capsulatus - which acts to upregulate the expression of the native cell's uptake hydrogenase in response to $\mathrm{H}_{2}$. The Rhodobacter system is composed of the $\mathrm{H}_{2}$-sensor protein (HupUV), a histidine kinase (HupT), a transcription regulator (HupR), and an uptake hydrogenase (HupSL). In the absence of $\mathrm{H}_{2}$, the sensor HupUV interacts with the kinase HupT inducing its autophosphorylation (Elsen et al. 1993). The activated kinase then phosphorylates the HupR regulator which downregulates the expression of the uptake hydrogenase. In the presence of $\mathrm{H}_{2}$, the kinase and the regulator proteins remain dephosphorylated, and the HupR regulator binds to and activates the S70 RNA polymerase(RNAP)-dependent transcription of hupSL. The regulator $h u p R$ is constitutively expressed at low levels in $R$. capsulatus (Dischert et al. 1999), whereas both hupUV and hupT are transcriptionally regulated from the hupT promoter and are transcribed at levels 50-fold lower than hupR (Vignais et al. 1997). Wecker et al. 2011 developed a screen in which the emGFP reporter protein is integrated behind the hupSL promoter of $R$. capsulatus. Hydrogensensing $R$. capsulatus cells were grown fermentatively in the dark in co-culture with Chlamydomonas on microtiter plates and the bacteria fluoresced in response to $\mathrm{H}_{2}$-production by the algae. The $\mathrm{H}_{2}$-producing algal cells are easily visualized for $\mathrm{H}_{2}$ induction, respond to as little as $200 \mathrm{pM} \mathrm{H}_{2}$ in solution ( $0.33 \mathrm{ppm}$ by volume in the headspace), and do not need to be lysed. This in situ $\mathrm{H}_{2}$-production detection system has been adapted to light-induced high-throughput analyses, and was shown to discriminate among a diversity of $\mathrm{H}_{2}$-production phenotypes (Wecker and Ghirardi 2014; Fig. 2).

\section{Molecular and metabolic engineering: what tools are available?}

Despite its use in algal research for several decades, Chlamydomonas remains a difficult platform for conducting genetic alterations. Genetic engineering relies on the expression of transgenes inserted at random into the genome via illegitimate recombination. The lack of tools for targeted gene insertion in green algae is a major impediment to the rapid progress of biological hydrogen production. Nuclear gene targeting and site-directed mutagenesis will be necessary to achieve fine-control over the hydrogen production machinery. A more controlled system would require replacement of the target gene via homologous recombination, which would enable Chlamydomonas to become a technical platform for the research community. Novel approaches are being developed to facilitate gene targeting, such as Cas9-based CRiSPR and knockouts of non-homologous pathways, as previously done in yeast (DiCarlo et al. 2013). 


\section{Integrated strategy}

It is clear that some of the most advantageous traits described in "Genetic engineering to overcome limitations to hydrogen production" and "Additional potential bottlenecks in hydrogen production" sections need to be incorporated into a single green algal strain to evaluate their additive effect on the rates and yields of $\mathrm{H}_{2}$ photoproduction. The use of genetics to cross different mutant lines should play an increasing role in further development of this technology. In our view, a mutant expressing a more $\mathrm{O}_{2}$-tolerant hydrogenase, such as the Clostridium acetobutylicum $\mathrm{Ca}$, the pgrll mutation, a truncated antenna, and an inducible Fd/hydrogenase fusion, represents one of the most promising genetic combinations to achieve long-term high-efficiency $\mathrm{H}_{2}$-producing activity, at this juncture. Obviously, other mutant constructs, containing for instance $\mathrm{O}_{2}$ sequesters and other proton gradient dissipators, are equally promising and worth pursuing. This research area is expanding rapidly, based on the premise and promise of a cost-effective carbon-neutral energy technology.

Acknowledgments We thank Dr. Matt Wecker for Fig. 2 courtesy, Al Hicks for his help with Fig. 1, and Tami Baldwin for formatting the document. This work was supported by the Office of Science (BER), U. S. Department of Energy (MLG and AD).

Open Access This article is distributed under the terms of the Creative Commons Attribution License which permits any use, distribution, and reproduction in any medium, provided the original author(s) and the source are credited.

\section{References}

Antal T, Mattila H, Hakala-Yatkin M, Tyystjarvi T, Tyystjarvi E (2010) Acclimation of photosynthesis to nitrogen deficiency in Phaseolus vulgaris. Planta 232(4):887-898. doi:10.1007/s00425$010-1227-5$

Chang C, King P, Ghirardi M, Kim K (2007) Atomic resolution Modeling of the ferredoxin :[FeFe] hydrogenase complex from Chlamydomonas reinhardtii. Biophys J 93(9):3034-3045. doi:10.1529/biophysj.107.108589

Chen H, Newton A, Melis A (2005) Role of SulP, a nuclear-encoded chloroplast sulfate permease, in sulfate transport and $\mathrm{H}-2$ evolution in Chlamydomonas reinhardtii. Photosynth Res 84(1-3):289-296. doi:10.1007/s11120-004-7157-y

Chien L, Kuo T, Liu B, Lin H, Feng T, Huang C (2012) Solar-tobioH $_{2}$ production enhanced by homologous overexpression of hydrogenase in green alga Chlorella sp. DT. Int J Hydrogen Energy 37(23):17738-17748

Chochois V, Constans L, Dauvillée D, Beyly A, Solivérès M, Ball S, Peltier G, Cournac L (2010) Relationships between PSIIindependent hydrogen bioproduction and starch metabolism as evidenced from isolation of starch catabolism mutants in the green alga Chlamydomonas reinhardtii. Int J Hydrogen Energy 35(19): 10731-10740

Chu H, Nguyen A, Debus R (1995) Amino acid residues that influence the binding of manganese or calcium to photosystem II. 1. The luminal inter-helical domains of the D1 polypeptide. Biochemistry-Us 34:5839-5958
Cinco R, MacInnis J, Greenbaum E (1993) The role of carbon dioxide in light-activated hydrogen production by Chlamydomonas reinhardtii. Photosynth Res 38(1):27-33

DiCarlo J, Norville J, Mali P, Rios X, Aach J, Church G (2013) Genome engineering in Saccharomyces cerevisiae using CRISPR-Cas systems. Nucleic Acids Res 41(7):4336-4343

Dischert W, Vignais P, Colbeau A (1999) The synthesis of Rhodobacter capsulatus HupSL hydrogenase is regulated by the two-component HupT/HupR system. Mol Microbiol 34(5):995-1006

Doebbe A, Rupprecht J, Beckmann J, Mussgnug J, Hallmann A, Hankamer B, Kruse O (2007) Functional integration of the HUP1 hexose symporter gene into the genome of $C$-reinhardtii: impacts on biological $\mathrm{H}_{2}$ production. J Biotechnol 131(1):27-33. doi:10.1016/j.jbiotec.2007.05.017

Doebbe A, Keck M, La Russa M, Mussgnug JH, Hankamer B, Tekçe E, Niehaus K, Kruse O (2010) The interplay of proton, electron, and metabolite supply for photosynthetic $\mathrm{H} 2$ production in Chlamydomonas reinhardtii. J Biol Chem 285(39):30247-30260

Elsen S, Richaud P, Colbeau A, Vignais P (1993) Sequence analysis and interposon mutagenesis of the hupT gene, which encodes a sensor protein involved in repression of hydrogenase synthesis in Rhodobacter capsulatus. J Bacteriol 175(22):7404-7412

Esquivel M, Pinto T, Marin-Navarro J, Moreno J (2006) Substitution of tyrosine residues at the aromatic cluster around the beta A-beta B loop of rubisco small subunit affects the structural stability of the enzyme and the in vivo degradation under stress conditions. Biochemistry-Us 45(18):5745-5753. doi:10.1021/ Bi052588y

Esquível MG, Amaro HM, Pinto TS, Fevereiro PS, Malcata FX (2011) Efficient $\mathrm{H}_{2}$ production via Chlamydomonas reinhardtii. Trends Biotechnol 29(12):595-600

Flores N, de Anda R, Flores S, Escalante A, Hernández G, Martínez A, Ramírez O, Gosset G, Bolívar F (2004) Role of pyruvate oxidase in Escherichia coli strains lacking the phosphoenolpyruvate:carbohydrate phosphotransferase system. J Microbiol Biotechnol 8(4):209-221

Florin L, Tsokoglou A, Happe T (2001) A novel type of iron hydrogenase in the green alga Scenedesmus obliquus is linked to the photosynthetic electron transport chain. J Biol Chem 276(9):6125-6132. doi:10.1074/jbc.M008470200

Flynn T, Ghirardi M, Seibert M (2002) Accumulation of $\mathrm{O}_{2}$-tolerant phenotypes in $\mathrm{H}_{2}$-producing strains of Chlamydomonas reinhardtii by sequential applications of chemical mutagenesis and selection. Int J Hydrogen Energy 27(11-12):1421-1430. doi:10. 1016/S0360-3199(02)00117-9

Frustaci J, O'Brian M (1992) Characterization of a Bradyrhizobium japonicum ferrochelatase mutant and isolation of the hemH gene. J Bacteriol 174(13):4223-4229

Gaffron H, Rubin J (1942) Fermentative and photochemical production of hydrogen in alage. J Gen Physiol 20(26):219-240

Ghirardi M, Togasaki R, Seibert M (1997) Oxygen sensitivity of algal $\mathrm{H}_{2}$-production. Appl Biochem Biotechnol 67(1-2):182

Ghirardi M, Dubini A, Yu J, Maness P (2009) Photobiological hydrogen-producing systems. Chem Soc Rev 38(1):52-61. doi: $10.1039 / \mathrm{b} 718939 \mathrm{~g}$

Happe T, Molser B, Naber J (1994) Induction, localization and metal content of hydrogenase in the green-alga Chlamydomonasreinhardtii. Eur J Biochem 222(3):769-774

Healey $F$ (1970) Hydrogen evolution by several algae. Planta 91(3):220-226

Hemschemeier A, Fouchard S, Cournac L, Peltier G, Happe T (2008) Hydrogen production by Chlamydomonas reinhardtii: an elaborate interplay of electron sources and sinks. Planta 227(2): 397-407

Hutchison R, Xiong J, Sayre R, Govindjee (1996) Construction and characterization of a photosystem II D1 mutant (arginine-269- 
glycine) of Chlamydomonas reinhardtii. Bba-Bioenergetics 1277(1-2):83-92. doi:10.1016/S0005-2728(96)00085-0

James B, Baum G, Perez J, Baum K (2008) Technoeconomic boundary analysis of biological pathways to hydrogen production. Subcontract Report NREL/SR-560-46674:235-239

Katsuda T, Ooshima H, Azuma M, Kato J (2006) New detection method for hydrogen gas for screening hydrogen-producing microorganisms using water-soluble wilkinson's catalyst derivative. J Biosci Bioeng 102(2):220-226

Kirst H, Garcia-Cerdan J, Zurbriggen A, Melis A (2012a) Assembly of the light-harvesting chlorophyll antenna in the green alga Chlamydomonas reinhardtii requires expression of the TLA2CpFTSY gene. Plant Physiol 158(2):930-945. doi:10.1104/pp. 111.189910

Kirst H, Garcia-Cerdan J, Zurbriggen A, Ruehle T, Melis A (2012b) Truncated photosystem chlorophyll antenna size in the green microalga Chlamydomonas reinhardtii upon deletion of the TLA3-CpSRP43 gene. Plant Physiol 160(4):2251-2260. doi:10. 1104/pp.112.206672

Kosourov S, Ghirardi M, Seibert M (2011) A truncated antenna mutant of Chlamydomonas reinhardtii can produce more hydrogen than the parental strain. Int $\mathrm{J}$ Hydrogen Energy 36(3):2044-2048. doi:10.1016/j.ijhydene.2010.10.041

Kruse O, Rupprecht J, Bader K, Thomas-Hall S, Schenk P, Finazzi G, Hankamer B (2005) Improved photobiological $\mathrm{H}_{2}$ production in engineered green algal cells. J Biol Chem 280(40):34170-34177

Lardans A, Förster B, Prásil O, Falkowski P, Sobolev V, Edelman M, Osmond C, Gillham N, Boynton J (1998) Biophysical, biochemical, and physiological characterization of Chlamydomonas reinhardtii mutants with amino acid substitutions at the $\mathrm{Ala}(251)$ residue in the D1 protein that result in varying levels of photosynthetic competence. J Biol Chem 273(18):11082-11091

Liebgott P, Leroux F, Burlat B, Dementin S, Baffert C, Lautier T, Fourmond V, Ceccaldi P, Cavazza C, Meynial-Salles I, Soucaille P, Fontecilla-Camps J, Guigliarelli B, Bertrand P, Rousset M, Leger $C$ (2010) Relating diffusion along the substrate tunnel and oxygen sensitivity in hydrogenase. Nat Chem Biol 6(1):63-70. doi: $10.1038 /$ nchembio. 276

Lin H, Liu B, Kuo T, Tsai H, Feng T, Huang C, Chien L (2013) Knockdown of PsbO leads to induction of HydA and production of photobiological $\mathrm{H}_{2}$ in the green alga Chlorella sp. DT. Bioresour Technol 143:154-162. doi:10.1016/j.biortech.2013. 05.101

Long H, King P, Ghirardi M, Kim K (2009) Hydrogenase/ferredoxin charge-transfer complexes: effect of hydrogenase mutations on the complex association. J Phys Chem A 113(16):4060-4067. doi:10.1021/jp810409z

Lucker B, Kramer D (2013) Regulation of cyclic electron flow in Chlamydomonas reinhardtii under fluctuating carbon availability. Photosynth Res 117(1-3):449-459. doi:10.1007/s11120-0139932-0

Melis A, Chen H (2005) Chloroplast sulfate transport in green algaegenes, proteins and effects. Photosynth Res 86(3):299-307. doi:10. 1007/s11120-005-7382-Z

Melis A, Zhang L, Forestier M, Ghirardi M, Seibert M (2000) Sustained photobiological hydrogen gas production upon reversible inactivation of oxygen evolution in the green alga Chlamydomonas reinhardtii. Plant Physiol 122(1):127-136. doi:10. 1104/Pp.122.1.127

Merchant S, Prochnik S, Vallon O, Harris E, Karpowicz S, Witman G, Terry A, Salamov A, Fritz-Laylin L, Marechal-Drouard L, Marshall W, Qu L, Nelson D, Sanderfoot A, Spalding M, Kapitonov V, Ren Q, Ferris P, Lindquist E, Shapiro H, Lucas S, Grimwood J, Schmutz J, Cardol P, Cerutti H, Chanfreau G, Chen C, Cognat V, Croft M, Dent R, Dutcher S, Fernandez E, Fukuzawa H, Gonzalez-Ballester D, Gonzalez-Halphen D,
Hallmann A, Hanikenne M, Hippler M, Inwood W, Jabbari K, Kalanon M, Kuras R, Lefebvre P, Lemaire S, Lobanov A, Lohr M, Manuell A, Meir I, Mets L, Mittag M, Mittelmeier T, Moroney J, Moseley J, Napoli C, Nedelcu A, Niyogi K, Novoselov S, Paulsen I, Pazour G, Purton S, Ral J, RianoPachon D, Riekhof W, Rymarquis L, Schroda M, Stern D, Umen J, Willows R, Wilson N, Zimmer S, Allmer J, Balk J, Bisova K, Chen C, Elias M, Gendler K, Hauser C, Lamb M, Ledford H, Long J, Minagawa J, Page M, Pan J, Pootakham W, Roje S, Rose A, Stahlberg E, Terauchi A, Yang P, Ball S, Bowler C, Dieckmann C, Gladyshev V, Green P, Jorgensen R, Mayfield S, Mueller-Roeber B, Rajamani S, Sayre R, Brokstein P, Dubchak I, Goodstein D, Hornick L, Huang Y, Jhaveri J, Luo Y, Martinez D, Ngau W, Otillar B, Poliakov A, Porter A, Szajkowski L, Werner G, Zhou K, Grigoriev I, Rokhsar D, Grossman A (2007) The Chlamydomonas genome reveals the evolution of key animal and plant functions. Science 318(5848):245-250. doi:10. 1126/science. 1143609

Meuser J, D'Adamo S, Jinkerson R, Mus F, Yang W, Ghirardi M, Seibert M, Grossman A, Posewitz M (2012) Genetic disruption of both Chlamydomonas reinhardtii [FeFe]-hydrogenases: insight into the role of HYDA2 in $\mathrm{H}_{2}$ production. Biochem Biophys Res Commun 317(2):704-709

Mitra M, Melis A (2010) Genetic and biochemical analysis of the TLA1 gene in Chlamydomonas reinhardtii. Planta 231(3):729-740. doi:10.1007/s00425-009-1083-3

Mulder D, Boyd E, Sarma R, Lange R, Endrizzi J, Broderick J, Peters J (2010) Stepwise [FeFe]-hydrogenase H-cluser assembly revealed in the structure of HydA(DeltaEFG). Nature 465(7295): 248-251

Mus F, Cournac L, Cardettini W, Caruana A, Peltier G (2005) Inhibitor studies on non-photochemical plastoquinone reduction and $\mathrm{H}_{2}$ photoproduction in Chlamydomonas reinhardtii. Bba-Bioenergetics 1708(3):322-332. doi:10.1016/j.bbabio.2005.05.003

Nixon P, Diner B (1992) Aspartate 170 of the photosystem II reaction center polypeptide D1 is involved in the assembly of the oxygen-evolving manganese cluster. Biochemistry-Us 31(3): 942-948

Noth J, Krawietz D, Hemschemeier A, Happe T (2013) Pyruvate:ferredoxin oxidoreductase is coupled to light-independent hydrogen production in Chlamydomonas reinhardtii. J Biol Chem 288(6): 4368-4377

Oey M, Ross I, Stephens E, Steinbeck J, Wolf J, Radzun K, Kügler J, Ringsmuth A, Kruse O, Hankamer B (2013) RNAi knock-down of LHCBM1, 2 and 3 increases photosynthetic $\mathrm{H}_{2}$ production efficiency of the green alga Chlamydomonas reinhardtii. PLoS ONE 8(4):e61375

Ohad N, Hirschberg J (1992) Mutations in the D1 subunit of photosystem II between quinone and herbicide binding sites distinguish. Plant Cell 4:273-282

Peden E, Boehm M, Mulder D, Davis R, Old W, King P, Ghirardi M, Dubini A (2013) Identification of global ferredoxin interaction networks in Chlamydomonas reinhardtii. J Biol Chem 288(49): 1-37. doi:10.1074/jbc.M113.483727

Pinto T, Malcata F, Arrabaça J, Silva J, Spreitzer R, Esquível M (2013) Rubisco mutants of Chlamydomonas reinhardtii enhance photosynthetic hydrogen production. Appl Microbiol Biotechnol 97(12):5635-5643

Polle J, Kanakagiri S, Melis A (2003) Tla1, a DNA insertional transformant of the green alga Chlamydomonas reinhardtii with a truncated light-harvesting chlorophyll antenna size. Planta 271(1):49-59

Posewitz M, King P, Smolinski S, Zhang L, Seibert M, Ghirardi M (2004a) Discovery of two novel radical S-adenosylmethionine proteins required for the assembly of an active $[\mathrm{Fe}]$ hydrogenase. J Biol Chem 279(24):25711-25720 
Posewitz M, Smolinski S, Kanakagiri S, Melis A, Seibert M, Ghirardi M (2004b) Hydrogen photoproduction Is attenuated by disruption of an isoamylase gene in Chlamydomonas reinhardtii. Plant Cell 16(8):2151-2163

Posewitz M, King P, Smolinski S, Smith R, Ginley A, Ghirardi M, Seibert M (2005) Identification of genes required for hydrogenase activity in Chlamydomonas reinhardtii. Biochem Soc $\mathrm{T}$ 33(Pt 1):102-104

Ruhle T, Hemschemeier A, Melis A, Happe T (2008) A novel screening protocol for the isolation of hydrogen producing Chlamydomonas reinhardtii strains. BMC Plant Biol 8(107):1471-2229

Scoma A, Krawietz D, Faraloni C, Giannelli L, Happe T, Torzillo G (2012) Sustained $\mathrm{H}_{2}$ production in a Chlamydomonas reinhardtii D1 protein mutant. J Biotechnol 157(4):613-619. doi:10.1016/j. jbiotec.2011.06.019

Seibert M, Flynn T, Benson D (2001) Method for rapid biohydrogen phenotypic screening of microorganisms using a chemochromic sensor. US Patent 6,277,589

Skillman J (2008) Quantum yield variation across the three pathways of photosynthesis: not yet out of the dark. Plant Cell 23(7): 2619-2630

Stapleton J, Swartz J (2010) Development of an in vitro compartmentalization screen for high-throughput directed evolution of [FeFe] hydrogenases. PLoS ONE 5(12):e15275. doi:10.1371/ journal.pone.0015275

Surzycki R, Cournac L, Peltiert G, Rochaix J (2007) Potential for hydrogen production with inducible chloroplast gene expression in Chlamydomonas. Proc Natl Acad Sci 104(44):17548-17553

Takahashi H, Clowez S, Wollman F, Vallon O, Rappaport F (2013) Cyclic electron flow is redox-controlled but independent of state transition. Nat Commun 4:1954. doi:10.1038/Ncomms2954

Tetali S, Mitra M, Melis A (2007) Development of the lightharvesting chlorophyll antenna in the green alga Chlamydomonas reinhardtii is regulated by the novel Tla1 gene. Planta 225(4):813-829. doi:10.1007/s00425-006-0392-z

Tolleter D, Ghysels B, Alric J, Petroutsos D, Tolstygina I, Krawietz D, Happe T, Auroy P, Adriano J, Beyly A, Cuine S, Plet J, Reiter I, Genty B, Cournac L, Hippler M, Peltier G (2011) Control of hydrogen photoproduction by the proton gradient generated by cyclic electron flow in Chlamydomonas reinhardtii. Plant Cell 23(7):2619-2630. doi:10.1105/tpc.111.086876
Torzillo G, Scoma A, Faraloni C, Ena A, Johanningmeier U (2009) Increased hydrogen photoproduction by means of a sulfurdeprived Chlamydomonas reinhardtii D1 protein mutant. Int J Hydrogen Energy 34(10):4529-4536

Van Lis R, Baffert C, Couté Y, Nitschke W, Atteia A (2013) Chlamydomonas reinhardtii chloroplasts contain a homodimeric pyruvate:ferredoxin oxidoreductase that functions with FDX1. Plant Physiol 161(1):57-71

Vignais P, Dimon B, Zorin N, Colbeau A, Elsen S (1997) HupUV proteins of Rhodobacter capsulatus can bind $\mathrm{H}_{2}$ : evidence from the H-D exchange reaction. J Bacteriol 179(1):290-292

Volgusheva A, Stenbjörn S, Fikret M (2013) Increased photosystem II stability promotes $\mathrm{H}_{2}$ production in sulfur-deprived Chlamydomonas reinhardtii. Proc Natl Acad Sci USA 110(18):7223-7228

Wecker MS, Ghirardi ML (2014) High-throughput biosensor discriminates between different algal $\mathrm{H}_{2}$-photoproducing strains. Biotechnol Bioeng. doi:10.1002/bit.25206

Wecker M, Meuser J, Posewitz M, Ghirardi ML (2011) Design of a new biosensor for algal $\mathrm{H}_{2}$ production based on the $\mathrm{H}_{2}$-sensing system of Rhodobacter capsulatus. Int $\mathrm{J}$ Hydrogen Energy 36(17):7404-7412

Wu S, Huang R, Xu L, Yan G, Wang Q (2010) Improved hydrogen production with expression of hemH and lba genes in chloroplast of Chlamydomonas reinhardtii. J Biotechnol 146(3):120-125

Wu S, Xu L, Huang R, Wang Q (2011) Improved biohydrogen production with an expression of codon-optimized hemH and lba genes in the chloroplast of Chlamydomonas reinhardtii. Bioresour Technol 102:2610-2616

Xiong J, Subramaniam S, Govindjee (1998) A knowledge-based three dimensional model of the photosystem II reaction center of Chlamydomonas reinhardtii. Photosynth Res 56(3) :229-254

Xu F, Ma W, Zhu X (2011) Introducing pyruvate oxidase into the chloroplast of Chlamydomonas reinhardtii increases oxygen consumption and promotes hydrogen production. Int J Hydrogen Energy 36(17):10648-10654

Yacoby I, Pochekailov S, Toporik H, Ghirardi ML, King PW, Zhang S (2011) Photosynthetic electron partitioning between $[\mathrm{FeFe}]$-hydrogenase and ferredoxin:NADP+-oxidoreductase (FNR) enzymes in vitro. Proc Natl Acad Sci USA 108(23): 9396-9401 